\title{
AÇÕES AFIRMATIVAS NO BRASIL: DESAFIOS E PERSPECTIVAS
}

\author{
FLÁVIA PIOVESAN \\ Pontifícia Universidade Católica de São Paulo
}

Resumo: Qual é o balanço das ações afirmativas na experiência brasileira? Como compreender as primeiras iniciativas de adoção de marcos legais instituidores das ações afirmativas? Qual tem sido o impacto da agenda global na ordem doméstica? Em que medida a Convenção sobre a Eliminação de todas as formas de Discriminação Racial e a Conferência de Durban fomentaram avanços internos? Quais são os principais desafios, dilemas e tensões das ações afirmativas? Quais são as possibilidades e perspectivas de construção da igualdade étnicoracial no caso brasileiro? São estas as questões centrais a inspirar este artigo.

Palavras-chave: ações afirmativas; direitos humanos; Convenção sobre a Eliminação de todas as formas de Discriminação Racial; igualdade racial; justiça racial.

\section{Direito à igualdade e direlto à diferença: sistema especial de proteção dos direitos humanos}

A ética emancipatória dos direitos humanos demanda transformação social, a fim de que cada pessoa possa exercer, em sua plenitude, suas potencialidades, sem violência e discriminação. É a ética que vê no outro um ser merecedor de igual consideração e profundo respeito, dotado do direito de desenvolver as potencialidades humanas, de forma livre, autônoma e plena. Enquanto um construído histórico, os direitos humanos não traduzem uma história linear, não compõem uma marcha triunfal, nem tampouco uma causa perdida. Mas refletem, a todo tempo, a história de um combate, ${ }^{1}$ mediante processos que abrem e consolidam espaços de luta pela dignidade humana. ${ }^{2}$

Sob a pespectiva histórica de construção dos direitos humanos, observa-se que a primeira fase de proteção desses direitos foi marcada pela tônica da proteção geral, que expressava o temor da diferença.

Testemunha a história que as mais graves violações aos direitos humanos tiveram como fundamento a dicotomia do "eu versus o outro", em que a diversidade era captada

\footnotetext{
Copyright (C) 2008 by Revista Estudos Feministas.

${ }^{1}$ Daniele LOCHAK, 2005, p. 116, citada por Celso LAFER, 2006, p. XXII.

2 Joaquín Herrera FLORES, [s.d.], p. 7.
} 
como elemento para aniquilar direitos. Vale dizer, a diferença era visibilizada para conceber ○ "outro" como um ser menor em dignidade e direitos, ou, em situações limites, um ser esvaziado mesmo de qualquer dignidade, um ser descartável, objeto de compra e venda (vide a escravidão) ou de campos de extermínio (vide o nazismo). Nesse sentido, merecem destaque as violações da escravidão, do nazismo, do sexismo, do racismo, da homofobia, da xenofobia e outras práticas de intolerância.

É nesse contexto que se afirma a chamada igualdade formal, a igualdade geral, genérica e abstrata, sob o lema de que "todos são iguais perante a lei". A título de exemplo, basta avaliar quem é o destinatário da Declaração Universal de 1948, bem como basta atentar para a Convenção para a Prevenção e Repressão ao Crime de Genocídio, também de 1948, que pune a lógica da intolerância pautada na destruição do "outro", em razão de sua nacionalidade, etnia, raça ou religião. Como leciona Amartya Sen, "a identidade pode ser tanto uma fonte de riqueza e conforto como de violência e terror". ${ }^{3}$

Torna-se, contudo, insuficiente tratar o indivíduo de forma genérica, geral e abstrata. Faz-se necessária a especificaçåo do sujeito de direito, que passa a ser visto em suas peculiaridades e particularidades. Nessa ótica, determinados sujeitos de direitos, ou determinadas violações de direitos, exigem uma resposta específica e diferenciada. Isto é, na esfera internacional, se uma primeira vertente de instrumentos internacionais nasce com a vocação de proporcionar uma proteção geral, genérica e abstrata, refletindo o próprio temor da diferença (que na era Hitler foi justificativa para o extermínio e a destruição), percebe-se, posteriormente, a necessidade de conferir a determinados grupos uma proteção especial e particularizada, em face de sua própria vulnerabilidade. Isso significa que a diferença não mais seria utilizada para a aniquilação de direitos, mas, ao revés, para a promoção de direitos.

Nesse cenário, por exemplo, a população afrodescendente, as mulheres, as crianças e demais grupos devem ser vistos nas especificidades e peculiaridades de sua condiçåo social. Ao lado do direito à igualdade, surge, também, como direito fundamental, o direito à diferença. Importa o respeito à diferença e à diversidade, o que thes assegura um tratamento especial.

Destacam-se, assim, três vertentes no que tange à concepção da igualdade: a) a igualdade formal, reduzida à fórmula "todos são iguais perante a lei" (que, ao seu tempo, foi crucial para abolição de privilégios); b) a igualdade material, correspondente ao ideal de justiça social e distributiva (igualdade orientada pelo critério sócio-econômico); e c) a igualdade material, correspondente ao ideal de justiça enquanto reconhecimento de identidades (igualdade orientada pelos critérios de gênero, orientação sexual, idade, raça, etnia e demais critérios).

Para Nancy Fraser, a justiça exige, simultaneamente, redistribuição e reconhecimento de identidades. Como atenta a autora,

O reconhecimento não pode se reduzir à distribuição, porque o status na sociedade não decorre simplesmente em função da classe. [...] Reciprocamente, a distribuição

\footnotetext{
${ }^{3}$ SEN, 2006, p. 4, tradução da editoria ("identity can be a source of richness and warmth as well as of violence and terror"). O autor ainda tece aguda crítica ao que denomina "a séria miniaturização dos seres humanos" ("serious miniaturization of human beings"), quando é negado o reconhecimento da pluralidade de identidades humanas, na medida em que as pessoas são "diferentes diversidades" ("diversily different") (SEN, 2006, p. XIII e XIV).
} 
não pode se reduzir ao reconhecimento, porque o acesso aos recursos não decorre simplesmente em função de status. ${ }^{4}$

No mesmo sentido, Boaventura de Souza Santos afirma que apenas a exigência do reconhecimento e da redistribuição permite a realização da igualdade. ${ }^{5}$

Ressalta-se, assim, o caráter bidimensional da justiça: redistribuição somada ao reconhecimento. $O$ direito à redistribuição requer medidas de enfrentamento da injustiça econômica, da marginalização e da desigualdade econômica, por meio da transformação nas estruturas sócio-econômicas e da adoção de uma política de redistribuição. De igual modo, o direito ao reconhecimento requer medidas de enfrentamento da injustiça cultural, dos preconceitos e dos padrões discriminatórios, por meio da transformação cultural e da adoção de uma política de reconhecimento. É à luz dessa política de reconhecimento que se pretende avançar na reavaliação positiva de identidades discriminadas, negadas e desrespeitadas; na desconstrução de estereótipos e preconceitos; e na valorização da diversidade cultural. ${ }^{6}$

Ainda Boaventura acrescenta: "temos o direito a ser iguais quando a nossa diferença nos inferioriza; e temos o direito a ser diferentes quando a nossa igualdade nos descaracteriza. Daí a necessidade de uma igualdade que reconheça as diferenças e de uma diferença que não produza, alimente ou reproduza as desigualdades".

É nesse cenário que as Nações Unidas aprovam, em 1965, a Convenção sobre a Eliminação de todas as formas de Discriminação Racial, ${ }^{8}$ ratificada por 170 Estados, entre eles o Brasil, que a ratificou em 27 de março de 1968.

Desde seu preâmbulo, essa Convenção assinala que qualquer "doutrina de superioridade baseada em diferenças raciais é cientificamente falsa, moralmente condenável, socialmente injusta e perigosa, inexistindo justificativa para a discriminação racial, em teoria ou prática, em lugar algum". Adiciona a urgência em se adotar todas as medidas necessárias para eliminar a discriminação racial em todas as suas formas e manifestações e para prevenir e combater doutrinas e práticas racistas.

O artigo $1^{\circ}$ da Convenção define a discriminação racial como "qualquer distinção, exclusão, restrição ou preferência baseada em raça, cor, descendência ou origem nacional ou étnica, que tenha o propósito ou o efeito de anular ou prejudicar o reconhecimento, gozo ou exercício em pé de igualdade dos direitos humanos e liberdades fundamentais". Vale dizer, a discriminação significa toda distinção, exclusão, restrição ou preferência que tenha por objeto ou resultado prejudicar ou anular o exercício, em igualdade de condições,

\footnotetext{
${ }^{4}$ Afirma Nancy Fraser: "O reconhecimento não pode se reduzir à distribuição, porque o status na sociedade não decorre simplesmente em função da classe. Tomemos o exemplo de um banqueiro afro-americano de Wall Street que não pode conseguir um taxi. Nesse caso, a injustiça da falta de reconhecimento tem pouco a ver com a má distribuição. [...] Reciprocamente, a distribuição não pode se reduzir ao reconhecimento, porque o acesso aos recursos não decorre simplesmente da função de status. Tomemos, como exemplo, um trabalhador industrial especializado, que fica desempregado em virtude do fechamento da fábrica em que trabalha, em vista de uma fusão corporativa especulativa. Nesse caso, a injustiça da má distribuição tem pouco a ver com a falta de reconhecimento. [...] Proponho desenvolver o que chamo concepção bidimensional da justiça. Essa concepção trata da redistribuição e do reconhecimento como perspectivas e dimensões distintas da justiça. Sem reduzir uma à outra, abarca ambas em um marco mais amplo" (FRASER, 2001, p. 5556).

${ }^{5}$ A respeito, ver SOUZA SANTOS, 2003a e 2003b.

' Ver Nancy FRASER, 1997; Axel HONNETH, 1996; Nancy FRASER e Axel HONNETH, 2003; Charles TAYLOR, 1994; Iris YOUNG, 1990; e Amy GUTMANN, 1994.

7 Ver SOUZA SANTOS, 2003a e 2003b.

${ }^{8}$ A Convenção foi adotada pela Resolução n. $2106 \mathrm{~A}(\mathrm{XX})$ da Assembléia Geral das Nações Unidas, em 21 de dezembro de 1965.
} 
dos direitos humanos e liberdades fundamentais, nos campos político, econômico, social, cultural e civil ou em qualquer outro campo. Logo, a discriminação significa sempre desigualdade.

Essa mesma lógica inspirou a definição de discriminação contra a mulher, quando da adoção da Convenção sobre a Eliminação de todas as formas de Discriminação contra a Mulher, pela ONU, em 1979.

A discriminação ocorre quando somos tratados iguais, em situações diferentes; e diferentes, em situações iguais.

Como enfrentar a problemática da discriminação?

No âmbito do Direito Internacional dos Direitos Humanos, destacam-se duas estratégias: a) a estratégia repressiva-punitiva (que tem por objetivo punir, proibir e eliminar a discriminação); e b) a estratégia promocional (que tem por objetivo promover, fomentar e avançar a igualdade).

Na vertente repressiva-punitiva, há a urgência em se erradicar todas as formas de discriminação. O combate à discriminação é medida fundamental para que se garanta $\circ$ pleno exercício dos direitos civis e políticos, como também dos direitos sociais, econômicos e culturais.

Se o combate à discriminação é medida emergencial à implementação do direito à igualdade, todavia, por si só, é medida insuficiente. É fundamental conjugar a vertente repressiva-punitiva com a vertente promocional.

Faz-se necessário combinar a proibição da discriminação com políticas compensatórias que acelerem a igualdade enquanto processo. Isto é, para assegurar a igualdade não basta apenas proibir a discriminação, mediante legislação repressiva. São essenciais as estratégias promocionais capazes de estimular a inserção e inclusão de grupos socialmente vulneráveis nos espaços sociais. Com efeito, a igualdade e a discriminação pairam sob o binômio inclusão-exclusão. Enquanto a igualdade pressupõe formas de inclusão social, a discriminação implica a violenta exclusão e intolerância à diferença e à diversidade. $O$ que se percebe é que a proibição da exclusão, em si mesma, não resulta automaticamente na inclusão. Logo, não é suficiente proibir a exclusão, quando o que se pretende é garantir a igualdade de fato, com a efetiva inclusão social de grupos que sofreram e sofrem um consistente padrão de violência e discriminação.

As ações afirmativas devem ser compreendidas não somente pelo prisma retrospectivo - no sentido de aliviar a carga de um passado discriminatório -, mas também prospectivo - no sentido de fomentar a transformação social, criando uma nova realidade.

A Convenção sobre a Eliminação de todas as formas de Discriminação Racial prevê, no artigo $1^{\circ}$, parágrafo $4^{\circ}$, a possibilidade de "discriminação positiva" (a chamada "ação afirmativa"), mediante a adoção de medidas es-peciais de proteção ou incentivo a grupos ou indivíduos, com vistas a promover sua ascensão na sociedade até um nível de equiparação com os demais. As ações afirmativas objetivam acelerar o processo de igualdade, com $\mathrm{o}$ alcance da igualdade substantiva por parte de grupos socialmente vulneráveis, como as minorias étnicas e raciais, entre outros grupos.

Importa acrescentar que a Convenção sobre a Eliminação de todas as formas de Discriminação contra a Mulher de 1979 , em seu artigo $4^{\circ}$, parágrafo $1^{\circ}$, também estabelece a possibilidade de os Estados-partes adotarem ações afirmativas, como medidas especiais e temporárias destinadas a acelerar a igualdade de fato entre homens e mulheres. Essa 
Convenção foi ratificada pelo Brasil em 1984. As Recomendações Gerais n. $5^{9}$ e $25^{10}$ do Comitê sobre a Eliminação de Discriminação contra a Mulher endossam a importância da adoção de tais ações, para que a mulher se integre na educação, na economia, na política e no emprego. O Comitê ainda recomenda que os Estados-partes velem para que as mulheres em geral, e os grupos de mulheres afetados em particular, participem da elaboração, aplicação e avaliação dos referidos programas. Recomenda, em especial, que se tenha um processo de colaboração e consulta com a sociedade civil e com organizações não-governamentais que representem distintos grupos de mulheres.

Desse modo, a Convenção sobre a Eliminação da Discriminação contra a Mulher também contempla a possibilidade jurídica de uso das ações afirmativas, pela qual os Estados podem adotar medidas especiais temporárias, com vistas a acelerar o processo de igualização de status entre homens e mulheres. Tais medidas cessarão quando alcançado o seu objetivo.

Cabe salientar que a Recomendação Geral n. XXV (2000) do Comitê sobre a Eliminação de todas as formas de Discriminação Racial traz uma nova perspectiva: alia a perspectiva racial à de gênero. Sob esta ótica, o Comitê entende que a discriminação racial atinge de forma diferenciada homens e mulheres, já que práticas de discriminação racial podem ser dirigidas a certos indivíduos especificamente em razão do seu sexo, como no caso da violência sexual praticada contra mulheres de determinada origem étnicoracial. A discriminação pode dificultar o acesso de mulheres a informações em geral, bem como obstar a denúncia das discriminações e violências que vierem a sofrer. O Comitê pretende monitorar como as mulheres que pertencem às minorias étnicas e raciais exercem seus direitos, avaliando a dimensão da discriminação racial a partir de uma perspectiva de gênero.

\section{Direito brasileiro e ações afirmativas}

Além das ações afirmativas contarem com o sólido amparo jurídico das Convenções sobre a Eliminação de todas as formas de Discriminação Racial e contra a Mulher, ambas ratificadas pelo Brasil, a ordem jurídica nacional, gradativamente, passa a introduzir marcos legais com o objetivo de instituir políticas de ações afirmativas.

A Constituição Federal de 1988, marco jurídico da transição democrática e da institucionalização dos direitos humanos no Brasil, estabelece importantes dispositivos que traduzem a busca da igualdade material. Como princípio fundamental, consagra, entre os objetivos do Brasil, construir uma sociedade livre, justa e solidária, mediante a redução das desigualdades sociais e a promoção do bem de todos, sem quaisquer formas de discriminação (artigo $3^{\circ}$, I, III e IV). Prevê expressamente para as mulheres e para as pessoas com deficiência a possibilidade de adoção de ações afirmativas. Nesse sentido, destacase o artigo $7^{\circ}$, inciso XX, que trata da proteção do mercado de trabalho da mulher, mediante incentivos específicos, bem como o artigo 37 , VII, que determina que a lei reservará percentual de cargos e empregos públicos para as pessoas com deficiência.

\footnotetext{
${ }^{9}$ A respeito da importância das ações afirmativas, destaca a Recomendação Geral n. 5 do Comitê: "O Comitê sobre a Eliminação de Discriminação contra a Mulher [...] recomenda que os Estados-partes façam maior uso de medidas especiais de caráter temporário como a ação afirmativa, o tratamento preferencial ou sistema de quotas para que a mulher se integre na educação, na economia, na política e no emprego".

${ }^{10}$ Nos termos da Recomendação Geral n. 25 do Comitê: "Os Estados-partes deverão incluir em suas Constituições ou em sua legislação nacional disposições que permitam a adoção de medidas especiais de caráter temporário".
} 
Acrescente-se ainda a chamada "Lei das cotas" de 1995 (Lei n. 9.100/95), que introduziu uma cota mínima de $20 \%$ das vagas de cada partido ou coligação para a candidatura de mulheres. Essa lei foi posteriormente alterada pela Lei 9.504 , de 30 de setembro de 1997, que, ao estabelecer normas para as eleições, dispôs que cada partido ou coligação deverá reservar o mínimo de $30 \%$ e o máximo de $70 \%$ para candidaturas de cada sexo.

Some-se também o Programa Nacional de Direitos Humanos (Decreto 1.904, de 13 de maio de 1996), que faz expressa alusão às políticas compensatórias, prevendo como meta o desenvolvimento de ações afirmativas em favor de grupos socialmente vulneráveis.

Observe-se que o próprio documento oficial brasileiro apresentado à Conferência das Nações Unidas contra o Racismo, em Durban (31 de agosto a 7 de setembro de 2001), defendeu, do mesmo modo, a adoção de medidas afirmativas para a população afrodescendente, nas áreas da educação e trabalho. O documento propôs a adoção de ações afirmativas para garantir o maior acesso de afrodescendentes às universidades públicas, bem como a utilização, em licitações públicas, de um critério de desempate que considerasse a presença de afrodescendentes, homossexuais e mulheres no quadro funcional das empresas concorrentes. A Conferência de Durban, em suas recomendações, pontualmente nos seus parágrafos 107 e 108, endossa a importância dos Estados em adotarem ações afirmativas, enquanto medidas especiais e compensatórias voltadas a aliviar a carga de um passado discriminatório daqueles que foram vítimas da discriminação racial, da xenofobia e de outras formas de intolerância correlatas.

Na experiência brasileira vislumbra-se a força catalisadora da Conferência de Durban no tocante às ações afirmativas, envolvendo não apenas os trabalhos preparativos pré-Durban, como especialmente a agenda nacional pós-Durban, que propiciou significativos avanços no debate público sobre o tema. Foi no processo pós-Durban que, por exemplo, acentuou-se o debate sobre a fixação de cotas para afrodescendentes em universidades, bem como sobre o chamado Estatuto da Igualdade Racial.

Em 2002, no âmbito da Administração Pública Federal, foi criado o Programa Nacional de Ações Afirmativas, "1 que contemplou medidas de incentivo à inclusão de mulheres, afrodescendentes e portadores de deficiência, como critérios de pontuação em licitações que beneficiem fornecedores que comprovem desenvolver políticas compatíveis com o programa. No mesmo ano, foi lançado o Programa Diversidade na Universidade, ${ }^{12}$ que estabeleceu a criação de bolsas de estudo e prêmios a alunos de instituições que desenvolvessem ações de inclusão no espaço universitário, além de autorizar o Ministério da Educação a estudar, implementar e apoiar outras ações que servissem ao mesmo fim. É nesse contexto que foram adotados programas de cotas para afrodescendentes em universidades - como é o caso da UERJ, UNEB, UnB, UFPR, entre outras. Posteriormente, em 2003 foi instituída a Política Nacional de Promoção da Igualdade Racial (PNPIR), que reforça a eficácia das ações afirmativas e determina a criação de diversos mecanismos de incentivo e pesquisas para melhor mapear a população afrodescendente, otimizando assim os projetos direcionados. Ainda naquele ano, foi criada a Secretaria Especial de Políticas de Promoção da Igualdade Racial, ${ }^{13}$ da Presidência da República, que auxilia o desenvolvimento de programas, convênios, políticas e pesquisas de interesse para a integração racial.

\footnotetext{
${ }^{11}$ Decreto Federal 4.228/02.

12 Lei $10.558 / 02$.

${ }^{13}$ Lei 10.678/03. No site da Presidência da República é possível acessar estudos e pesquisas que abordam essa temática, além de notícias e outras informações: www.planalło.gov.br/seppir/.
} 
Ainda no âmbito da Federação, não apenas a União, mas também os Estados passaram a adotar políticas e planos de promoção da igualdade material, muitos deles sob a inspiração dos já apresentados, mas outros específicos para as estruturas e realidades regionais. Um marco importante é a Constituição do Estado da Bahia, ${ }^{14}$ que traz capítulos específicos a respeito do afrodescendente e do índio. Estados como o Paraná ${ }^{15}$ e Santa Catarina $^{16}$ prescreveram sanções administrativas às empresas que praticarem atos discriminatórios - no primeiro contra a mulher e no segundo por questões raciais -, prevendo a impossibilidade de participar em licitações e convênios públicos até a proibição de parcelamento de débitos, entre outras medidas.

Outros Estados também têm adotado políticas de ações afirmativas, como São Paulo, com a Política de Ações Afirmativas para Afrodescendentes ${ }^{17}$ e o Grupo de Trabalho ${ }^{18}$ criado para introduzir mecanismos de incentivo em licitações e concursos públicos.

Além disso, adicione-se o Estatuto da Igualdade Racial, ${ }^{19}$ que, pelo período de dez anos, propõe: a fixação de cotas raciais para cargos da administração pública federal e estadual; a valorização da herança cultural afrodescendente na história nacional; cota para a participação de afrodescendentes em propagandas, filmes e programas; a inserção do quesito "cor/raça" no sistema de saúde; a reserva de vagas para afrodescenentes e povos indígenas em universidades federais; a composição étnico-racial de empresas como critério para desempate em licitações públicas; e o dever de adotar programas de promoção de igualdade racial às empresas que se beneficiam de incentivos governamentais.

\section{Ações afirmativas no Brasil: desafios e perspectivas}

\section{O debate público a respeito das ações afirmativas no Brasil tem sido marcado por} cinco dilemas e tensões. ${ }^{20}$

O primeiro dilema atém-se à discussão acerca da "igualdade formal versus igualdade material". Argumentam os opositores das ações afirmativas que seriam elas atentatórias ao princípio da igualdade formal, reduzido à fórmula "todos são iguais perante a lei", na medida em que instituiriam medidas discriminatórias. Como já exposto, as ações afirmativas orientam-se pelo valor da igualdade material, substantiva.

Uma segunda tensão envolve o antagonismo "políticas universalistas versus políticas focadas". Isto é, para os críticos das ações afirmativas, as mesmas demandariam políticas focadas, favoráveis a determinados grupos socialmente vulneráveis, o que fragilizaria a

\footnotetext{
${ }^{14}$ Ver: www.al.ba.gov.br/infserv/legislacao/constituicao2005.pdf.

${ }^{15}$ Lei 10.183/92: www.pr.gov.br/casacivil/legislacao.shtml.

${ }^{16}$ Lei 10.064/96: www.alesc.sc.gov.br.

${ }^{17}$ Decreto 48.328/06: www.legislacao.sp.gov.br/legislacao/index.htm.

${ }_{18}$ Decreto 50.782/06: www.legislacao.sp.gov.br/legislacao/index.htm.

${ }^{19}$ Em janeiro de 2007, o Estatuto encontrava-se tramitando na Câmara dos Deputados como PL-6264/2005, e pode ser encontrado diretamente pelo link: www.camara.gov.br-sileg-integras-359794.pdf. A proposta tem gerado acirrada polêmica no Brasil, como ilustram os artigos "Todos têm direitos iguais na República", de Ade Daher Filho e outros, Folha de S. Paulo, p. A3, 29 jun. 2006; "Intelectuais assinam manifesto contra o Estatuto da Igualdade Racial", O Estado de S. Paulo, p. A12, 30 jun. 2006; e "Estatuto da Igualdade Racial: Lula revê apoio", O Estado de S. Paulo, p. A8, 7 jul. 2006.

${ }^{20}$ Como exemplo, há dezenas de ações judiciais propostas contra cotas para afrodescendentes em universidades (ver, a título ilustrativo, TRF1 - AC 2006.33.00.002978-0/BA e AMS 2003.33.00.007199-9/BA, TRF4 AC 2005.70.00.013067-9), bem como a ação direta de inconstitucionalidade n. 2.858, ajuizada perante o Supremo Tribunal Federal pela Confederação dos Estabelecimentos de Ensino (CONFENEN) contra leis estaduais que instituíram cotas no Estado do Rio de Janeiro. A mídia tem explorado muito esse tema, com diversos artigos publicados (ver clipping da SEPPIR, www.planalto.gov.br/seppir/, para artigos da mídia privada, e o site da Radiobrás para a cobertura oficial: www.agenciabrasil.gov.br/assunto_view?titulo=igualdade\%20racial).
} 
adoção das políticas universalistas. A resposta a essa crítica é que nada impediria a adoção de políticas universalistas combinadas com políticas focadas. Além disso, estudos e pesquisas demonstram que a mera adoção de políticas universalistas não tem sido capaz de reduzir as desigualdades raciais, que se mantêm em padrões absolutamente estáveis ao longo de sucessivas gerações.

Uma terceira crítica apresentada concerne aos beneficiários das políticas afirmativas, considerando os critérios "classe social" e "raça/etnia". Aqui a tensão envolve, de um lado, o branco pobre, e, de outro, o afrodescendente de classe média. Ora, a complexa realidade brasileira vê-se marcada por um alarmante quadro de exclusão social e discriminação como termos interligados a compor um ciclo vicioso, em que a exclusão implica discriminação e a discriminação implica exclusão.

Outra tensão diz respeito ao argumento de que as ações afirmativas gerariam a "racialização" da sociedade brasileira, com a separação crescente entre brancos e afrodescendentes, acirrando as hostilidades raciais. Quanto a esse argumento, cabe ponderar que, se "raça" e "etnia" sempre foram critérios utilizados para exclusão de afrodescendentes no Brasil, que sejam agora utilizados, ao revés, para a sua necessária inclusão.

Um quinto dilema, especificamente no que se refere às cotas para afrodescendentes em universidades, atém-se à autonomia universitária e à meritocracia, que restariam ameaçadas pela imposição de cotas. Contudo, o impacto das cotas não seria apenas reduzido ao binômio inclusão/exclusão, mas também permitiria o alcance de um objetivo louvável e legítimo no plano acadêmico - que é a riqueza decorrente da diversidade. As cotas fariam com que as universidades brasileiras deixassem de ser territórios brancos, com a crescente inserção de afrodescendentes, com suas crenças e culturas, o que em muito contribuiria para uma formação discente aberta à diversidade e pluralidade. Dados do IPEA revelam que menos de $2 \%$ dos estudantes afrodescendentes estão em universidades públicas ou privadas. Isso faz com que as universidades sejam territórios brancos. A universidade é um espaço de poder, já que o diploma pode ser um passaporte para ascensão social. É fundamental democratizar o poder e, para isso, há que se democratizar o acesso ao poder, vale dizer, o acesso ao passaporte universitário.

O debate público das ações afirmativas tem ensejado, de um lado, aqueles que argumentam constituírem elas uma violação de direitos, e, de outro lado, os que advogam serem elas uma possibilidade jurídica ou mesmo um direito. A respeito, note-se que o anteprojeto de Convenção Interamericana contra o Racismo e toda forma de Discriminação e Intolerância, proposto pelo Brasil no âmbito da OEA, estabelece o direito à discriminação positiva, bem como o dever dos Estados de adotar medidas ou políticas públicas de ação afirmativa e de estimular a sua adoção no âmbito privado.

Por fim, em um país em que os afrodescendentes são $64 \%$ dos pobres e $69 \%$ dos indigentes (dados do IPEA), ${ }^{21}$ em que no índice de desenvolvimento humano geral (IDH, 2000) figura em $74^{\circ}$ lugar, mas que, sob o recorte étnico-racial, o IDH relativo à população afrodescendente $\mathrm{O}$ indica na $108^{a}$ posição (enquanto $\mathrm{O} \mathrm{IDH}$ relativo à população branca o indica na $43^{a}$ posição), ${ }^{22}$ faz-se essencial a adoção de ações afirmativas em benefício da população afrodescendente, em especial nas áreas da educação e do trabalho. Note-se que, de acordo com o International Development Bank, há aproximadamente 190 milhões de afrodescendentes nas Américas, correspondendo a $25 \%$ da população da

${ }^{21}$ Ver: "Ipea afirma que racismo só será combatido com política específica", Folha de S. Paulo, p. A6, 8 jul. 2001.

22 Ver: Marcelo PAIXÃO, 2000. 
região, que enfrenta um legado histórico de exclusão social, desigualdade estrutural e grave discriminação.

Considerando as especificidades do Brasil, que é o segundo país do mundo com o maior contingente populacional afrodescendente ( $45 \%$ da população brasileira, perdendo apenas para a Nigéria), tendo sido, contudo, o último país do mundo ocidental a abolir a escravidão, faz-se urgente a aplicação de medidas eficazes para romper com o legado histórico de exclusão étnico-racial e com as desigualdades estruturantes que compõem a realidade brasileira.

Se no início este texto acentuava que os direitos humanos não são um dado, mas um construído, enfatiza-se agora que as violações a estes direitos também o são. Isto é, as violações, as exclusões, as discriminações, as intolerâncias, os racismos, as injustiças raciais são um construído histórico, a ser urgentemente desconstruído, sendo emergencial a adoção de medidas emancipatórias para transformar este legado de exclusão étnico-racial e compor uma nova realidade.

Destacam-se, nesse sentido, as palavras de Abdias do Nascimento, ao apontar para a necessidade da

inclusão do povo afro-brasileiro, um povo que luta duramente há cinco séculos no país, desde os seus primórdios, em favor dos direitos humanos. É o povo cujos direitos humanos foram mais brutalmente agredidos ao longo da história do país: o povo que durante séculos não mereceu nem o reconhecimento de sua própria condição humana.

A implementação do direito à igualdade racial há de ser um imperativo éticopolítico-social capaz de enfrentar o legado discriminatório que tem negado à metade da população brasileira o pleno exercício de seus direitos e liberdades fundamentais. ${ }^{23}$

\section{Referênclas bibliográficas}

FLORES, Joaquín Herrera. Direitos humanos, interculturalidade e racionalidade de resistência. [s.d.] Mimeo.

FRASER, Nancy. "From Redistribution to Recognition? Dilemmas of Justice in a Postsocialist Age." In: . Justice Interruptus. Critical Reflections on the "Postsocialist" Condition. New York and London: Routledge, 1997. p. 11-40.

. "Redistribución, reconocimiento y participación: hacia un concepto integrado de la justicia". In: UNESCO. Informe Mundial sobre la Cultura - 2000-2001. Ediciones Unesco, 2001. p. 55-56.

FRASER, Nancy, and HONNETH, Axel. Redistribution or Recognition? A Political-Philosophical Exchange. London and New York: Verso, 2003.

GUTMANN, Amy (ed.). Multiculturalism: Examining the Politics of Recognition. Princeton: Princeton University Press, 1994.

HONNETH, Axel. The Struggle for Recognition: The Moral Grammar of Social Conflicts. Cambridge, Massachussets: MIT Press, 1996.

LAFER, Celso. "Prefácio". In: PIOVESAN, Flávia. Direitos humanos e justiça internacional. São Paulo: Saraiva, 2006, p. XXII.

LOCHAK, Daniele. Les droits de l'homme. Paris: La Découverte, 2005.

PAIXÃO, Marcelo (Coord.). Brasil 2000 - Novos marcos para as relações raciais. Federação de Órgãos para Assistência Social e Educacional (FASE), 2000. Projeto.

${ }^{23}$ Um especial agradecimento é feito ao Paulo Dallari, pela preciosa pesquisa a este texto. 
PIOVESAN, Flávia. Direitos humanos e justiça internacional: estudo comparativo dos sistemas interamericano, europeu e africano. São Paulo: Saraiva, 2006.

. Direitos humanos e o direito constitucional internacional. 10. ed. São Paulo: Saraiva, 2009a.

. Temas de direitos humanos. 3. ed. São Paulo: Saraiva, 2009b.

PIOVESAN, Flávia; MARTINS DE SOUZA, Douglas (Coords.). Ordem jurídica e igualdade étnicoracial. Brasília: Seppir, 2006.

SANTOS, Sales Augusto dos. Ações afirmativas e combate ao racismo nas Américas. Brasília: Ministério da Educação, 2005.

SARMENTO, Daniel; IKAWA, Daniela; PIOVESAN, Flavia (Coords.). Igualdade, diferença e direitos humanos. Rio de Janeiro: Lúmen Júris, 2008.

SEN, Amartya. Identity and Violence: The Illusion of Destiny. New York and London: W.W.Norton \& Company, 2006.

SOUZA SANTOS, Boaventura. "Introdução: para ampliar o cânone do reconhecimento, da diferença e da igualdade". In: Reconhecer para libertar: os caminhos do cosmopolitanismo multicultural. Rio de Janeiro: Civilização Brasileira, 2003a. p. 56.

. "Por uma concepção multicultural de direitos humanos". In: . Reconhecer para libertar: os caminhos do cosmopolitanismo multicultural. Rio de Janeiro: Civilização Brasileira, 2003b. p. 429-461.

TAYLOR, Charles. "The Politics of Recognition". In: GUTMANN, Amy (ed.). Multiculturalism: Examining the Politics of Recognition. Princeton: Princeton University Press, 1994. p. 2573.

YOUNG, Iris. Justice and the Politics of Difference. Princeton: Princeton University Press, 1990.

[Recebido em novembro de 2008 e aceito para publicação em dezembro de 2008]

\section{Affirmative Action in Brazil: Challenges and Prospects}

Abstract: How do we take stock of affirmative action in Brazil? How should we understand the first initiatives of introduction of a legal framework that institutes affirmative action? What has been the impact of the global agenda on the domestic order? To what extent have the Convention on the Elimination of All Forms of Racial Discrimination and the Conference of Durban fostered domestic progress? What are the key challenges, dilemmas and tensions facing affirmative action? What are the possibilities and prospects for the attainment of ethnical and racial equity in Brazil? These are the key questions that inspire this paper.

Key Words: Affirmative Action; Human Rights; Convention on the Elimination of All Forms of Racial Discrimination; Racial Equality; Racial Justice. 